\title{
Recommender System Based on Expert and Item Category
}

\section{Thanaphon Phukseng ${ }^{a}$ and Sunantha Sodsee ${ }^{\mathrm{b}, *}$}

Faculty of Information Technology, King Mongkut's University of Technology North Bangkok, Bangkok 10800, Thailand

E-mail: athanaphon134@yahoo.com, bsunanthas@kmutnb.ac.th (Corresponding author)

\begin{abstract}
The objective of this study was to introduce the recommender system based on expert and item category to match the right items to users. In this study, the expert identification was divided into 3 techniques which were 1) the experts from social network technique 2) the experts from the frequency of rating technique and 3) the experts from other user's preferences. To filter the expert users by using the frequency of rating technique and the experts from other user's preferences technique, data about item category is used. For evaluation in this study, the researcher used Epinion for the performance testing to find out errors and accuracies in the prediction process. The results of this study showed that all the presented techniques had mean absolute error score at about 0.15 and 85 percentages of accuracy, especially the expert identification combining with item category, it can reduce 60 percentages of the duration of recommendation creating.
\end{abstract}

Keywords: Recommender System, Expert, Social Network, Frequency of Rating, User Like, Item Category.

ENGINEERING JOURNAL Volume 22 Issue 2

Received 14 June 2017

Accepted 7 February 2018

Published 30 March 2018

Online at http://www.engj.org/

DOI:10.4186/ej.2018.22.2.157 


\section{Introduction}

Currently, the information technology has been fast developed because of the growth of the internet and 2.0 website [1]. It causes a proliferation of information and news leading to a problem called "Information Overload" which has multiple effects including an effect for E-Commerce. The information overload originates the difficult determining to purchase the products and services for many users [2].

So the recommender system has occurred to suggest products or services [3] match the right items with the user's preferences. One of the popular approach used to create the recommendation is the collaborative filtering which analyzes the profile similarities among the users [4]. However, there are still some problems of recommender system; for example, data sparsity, cold start problem, and the requirement to improve accuracy for giving recommendation [5]. Therefore, there is the combination of many approaches to creating recommender system, to be ready for problems, and to improve the performance of recommendation.

The purpose of this study was to present a creation of recommender system based on expert and item category because the expert recommendation is more reliable than friends or people [6], and the item category can help improve a performance of recommendation [7]. The researcher also tested an evaluation of performance for error and accuracy in prediction.

The content of this study is arranged as follows: Section 2 is Related work, Section 3 is Proposed approach, Section 4 is Experiment, and the last section is Conclusion and Discussion.

\section{Related Work}

In this section, the details about recommender system are presented, including the related studies regarding the recommender system based on expert and Item category that are as following.

Recommender system provides products or services suggestion, personalized for users by predicting the preferences of users which base on user's behavior, product attribute, and the product satisfaction of users [8].

The approaches of recommender system can be classified into 3 main types [9]. 1) Content - based filtering which recommends an item similar to the user preferences and product attribute in usage history. 2). Collaborative filtering, it is an item recommendation that considers information from similar profiles between users. 3). Hybrid technique, it is the combination of all recommender system approaches to solve the problems from reciprocal, especially, the collaborative filtering which is extensively used and requires item rating to calculate the similarities among the users. However, the collaborative filtering consists in some limitations [10]. Data sparsity is a lack of essential data to create an item recommendation. Cold start problem is the problem when there are some new users or new items entering the system, and there is insufficient data for recommendation. Moreover, there is still the requirement to improve accuracy for giving recommendation, so the combination of other approaches is applied to this approach to solve all above problems or to improve information for recommendation, and this study is focused on recommender system based on expert and item category.

An expert is a person that has knowledge and specialization in specific field, and opinion from this person can be useful [11], [12]. The research about recommender system based on expert showed on Table1.

Table 1. Research about recommender system based on expert approach.

\begin{tabular}{|c|l|c|c|}
\hline Authors & \multicolumn{1}{|c|}{ Title } & Pros & Cons \\
\hline $\begin{array}{c}\text { Martín- } \\
\text { Vicente et } \\
\text { al. [13] }\end{array}$ & $\begin{array}{l}\text { Improving e-Commerce } \\
\text { Collaborative Recommendations by } \\
\text { Semantic Inference of Neighbors } \\
\text { Practical Expertise }\end{array}$ & $\begin{array}{c}\text { Semantic approach is } \\
\text { utilised to get a } \\
\text { measurement of } \\
\text { practical expertise. }\end{array}$ & $\begin{array}{c}\text { The research does not } \\
\text { demonstrate } \\
\text { effectiveness }\end{array}$ \\
\hline Li et al. [14] & $\begin{array}{l}\text { An approach to expert } \\
\text { recommendation based on fuzzy } \\
\text { linguistic method and fuzzy text } \\
\text { classification in knowledge } \\
\text { management systems }\end{array}$ & $\begin{array}{c}\text { Fuzzy linguistic and } \\
\text { Fuzzy text classification } \\
\text { techniques are used for } \\
\text { expert identification. }\end{array}$ & $\begin{array}{c}\text { This research only } \\
\text { focuses on content- } \\
\text { based recommendation } \\
\text { approach. }\end{array}$ \\
\hline $\begin{array}{c}\text { Afzal and } \\
\text { Maurer [15] }\end{array}$ & $\begin{array}{l}\text { Expertise Recommender System for } \\
\text { Scientific Community }\end{array}$ & $\begin{array}{c}\text { Data mining techniques } \\
\text { are utilised to analyse }\end{array}$ & $\begin{array}{c}\text { The proposed process } \\
\text { focuses on which is not }\end{array}$ \\
\hline
\end{tabular}




\begin{tabular}{|c|l|c|c|}
\hline Authors & \multicolumn{1}{|c|}{ Title } & Pros & Cons \\
\hline Liao et al. \\
[16] & $\begin{array}{l}\text { Understanding experts' and novices' } \\
\text { expertise judgment of twitter users } \\
\text { the factors of expertise } \\
\text { and determine the } \\
\text { weight of each factor. }\end{array}$ & $\begin{array}{c}\text { The research presents } \\
\text { the concept of expert } \\
\text { and amateur } \\
\text { identification by twitter } \\
\text { analysis. }\end{array}$ & $\begin{array}{c}\text { The proposed process } \\
\text { focuses on which are } \\
\text { not recommended } \\
\text { products to the experts. }\end{array}$ \\
\hline $\begin{array}{c}\text { Song et al. } \\
\text { [17] }\end{array}$ & $\begin{array}{l}\text { Determining user expertise for } \\
\text { improving recommendation } \\
\text { performance }\end{array}$ & $\begin{array}{c}\text { The research proposes } \\
\text { an evaluation of } \\
\text { experts' skills as } \\
\text { followed: Early } \\
\text { Adoption (EA), Heavy } \\
\text { Access (HA), and } \\
\text { Niche-item Access } \\
\text { (NA). }\end{array}$ & $\begin{array}{c}\text { The accuracy values of } \\
\text { the recommendation } \\
\text { are rather low. }\end{array}$ \\
\hline Li et al. [18] & $\begin{array}{l}\text { A social recommender mechanism } \\
\text { for improving knowledge sharing in } \\
\text { online forums }\end{array}$ & $\begin{array}{c}\text { The research presents } \\
\text { the concept of online } \\
\text { forum analysis for } \\
\text { expert identification. }\end{array}$ & $\begin{array}{c}\text { The proposed process } \\
\text { only focuses on } \\
\text { content-based } \\
\text { recommendation } \\
\text { approach and took } \\
\text { rather a long time to } \\
\text { process. }\end{array}$ \\
\hline Davoodi et \\
al. [19]
\end{tabular}

It states that mostly the outcome is about expert recommendation, but there are some recommendations of items. They used content-based technique, but in this research, the researcher will more focus on collaborative filtering approach.

For the related studies about item category in this research, the researcher used the following studies that showed on Table 2.

Table 2. Research about recommender system based on item category approach.

\begin{tabular}{|c|l|c|c|}
\hline Authors & \multicolumn{1}{|c|}{ Title } & Pros & Cons \\
\hline $\begin{array}{c}\text { Albadavi } \\
\text { and } \\
\text { Shahbazi } \\
{[1]}\end{array}$ & $\begin{array}{l}\text { A hybrid recommendation } \\
\text { technique based on product } \\
\text { category attributes }\end{array}$ & $\begin{array}{c}\text { Product taxonomy is } \\
\text { applied to create a } \\
\text { multi-level product } \\
\text { category. }\end{array}$ & $\begin{array}{c}\text { Each item is subdivided } \\
\text { into unequal levels } \\
\text { which effects on item } \\
\text { category classification. }\end{array}$ \\
\hline $\begin{array}{c}\text { Sang-Min } \\
\text { and Yo-Sub } \\
{[20]}\end{array}$ & $\begin{array}{l}\text { A Content Recommendation } \\
\text { System Based on Category } \\
\text { Correlations }\end{array}$ & $\begin{array}{c}\text { This research can } \\
\text { support product divided } \\
\text { into multi -category. }\end{array}$ & $\begin{array}{c}\text { Calculating relationship } \\
\text { among product types } \\
\text { requires more time. }\end{array}$ \\
\hline $\begin{array}{c}\text { Wei et al. } \\
{[21]}\end{array}$ & $\begin{array}{l}\text { Item-Based Collaborative Filtering } \\
\text { Recommendation Algorithm } \\
\text { Combining Item Category with }\end{array}$ & $\begin{array}{c}\text { Products are } \\
\text { subcategorised and } \\
\text { relationship or the item } \\
\text { category is considered. }\end{array}$ & $\begin{array}{c}\text { Similarity computation } \\
\text { process is complex and } \\
\text { requires multiple } \\
\text { parameter. }\end{array}$ \\
\hline $\begin{array}{c}\text { Zhang et al. } \\
\text { [7] }\end{array}$ & $\begin{array}{l}\text { A random-walk based } \\
\text { recommendation algorithm } \\
\text { considering item categories }\end{array}$ & $\begin{array}{c}\text { Presentation of category } \\
\text { ranking creates a } \\
\text { recommendation for } \\
\text { algorithm. }\end{array}$ & $\begin{array}{c}\text { The proposed method } \\
\text { takes a lot of time to } \\
\text { calculate the category } \\
\text { rating. }\end{array}$ \\
\hline
\end{tabular}




\begin{tabular}{|c|l|c|c|}
\hline Authors & \multicolumn{1}{|c|}{ Title } & Pros & Cons \\
\hline $\begin{array}{c}\text { Thanaphon } \\
\text { et al. [22] }\end{array}$ & $\begin{array}{l}\text { Applying Item Category Rating in } \\
\text { Recommendation Systems }\end{array}$ & $\begin{array}{c}\text { It is recommended in } \\
\text { category level and easily } \\
\text { calculated. }\end{array}$ & $\begin{array}{c}\text { The accuracy values of } \\
\text { the recommendation } \\
\text { are rather low }\end{array}$ \\
\hline
\end{tabular}

From all related studies above shows the advantages and disadvantages of the item categories used in each research. Moreover, they prove that the performance of recommendation can be improved by item category. Therefore, in this research, the researcher focuses on applying item category in recommender system.

\section{Proposed Approach}

In this section, the researcher is covering the detail of recommender system based on experts and item category. It consists of 3 processes that are expert identification, expert neighbor filtering, and prediction. The essential data consists in1) User - Item matrix, 2) User rating, 3) social network data, 4) item category, and 5) item database as shown in Fig. 1.

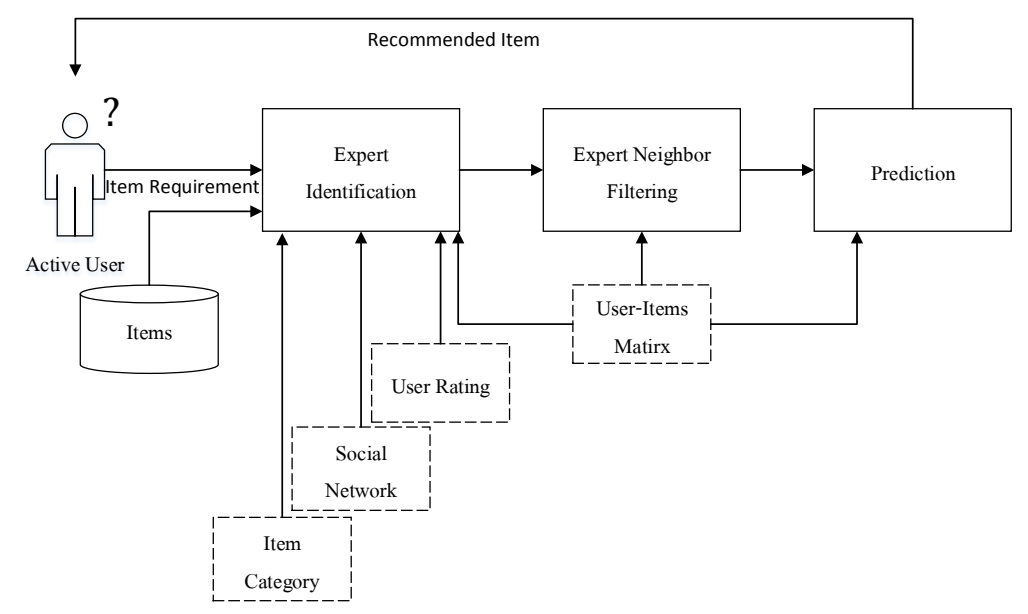

Fig. 1. Recommender system based on expert and item category.

\subsection{Expert Identification Process}

This process focuses on identifying expert users to recommended products. There are 3 types of experts in this study as followed, 1) the experts from social network, 2) the experts from frequency rating, and 3) the experts from the other's user preferences. The process starts from the system noticed by the active user's demanding in product. The system will match that product with target items that the users want to get the recommendation in the database. After that, expert users will be identified to recommended products as shown in Fig. 2. 


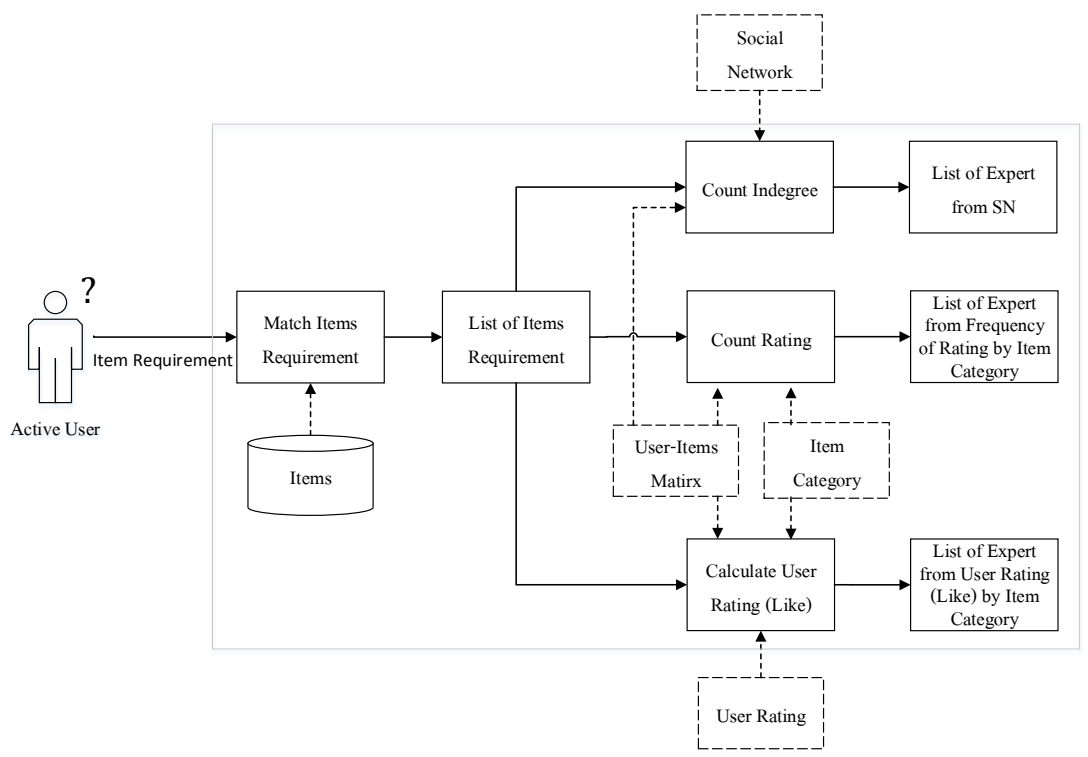

Fig. 2. Expert identification process.

\subsubsection{Expert from social network}

It is the expert consideration from reputation. The more famous is the more they have followers. The social network data in this research is analyzed by Graph theory [23]. Indegree of each user is significant because the indegree number is represent number of followers which is as reputation in each user. Network graph, where $G=(V, E)$ is a graph without loops, so $V$ is the set of users, and $E$ is the set of edges represented connection among users. Graph $G$ is directed graph for indegree, which can be shown in [24].

$$
\mathrm{C}_{\mathrm{d}}^{\text {in }}(\mathrm{A})=\operatorname{degree}^{\text {in }}(\mathrm{A})
$$

where degree $e^{\text {in }}(A)=|\{B \in V \mid(B, A) \in E\}|$ is quantity of user $B$ moving forward to user $A$. From this method, the researcher got expert user lists from social network.

\subsubsection{Expert from frequency of rating by item category}

It is an expert consideration criteria that users will be considered as experts from the product rating frequency. The idea is the user with more product rating frequency will be more experienced. The products that are relevant target product will be filtered. Therefore, item category is significant in this research. The frequency rated target products and the product in the same category are counted in each user, shown in this equation.

$$
\text { FreCate }_{A}=\sum_{i=1}^{N} n_{A, i} ; n_{A, i}=\left\{\begin{array}{c}
1 \text { Item } \in \text { Target Item or Items are Same Target Item Category } \\
0 \text { other }
\end{array}\right.
$$

where FreCate $_{A}$ is frequency of item rating of user $A$ in item category. $n_{A, i}$ is score that is from user $A$ rating by item category, which is $i \in\{1, \ldots, N\}$, When $N$ represents the number of all items. From this method, the researcher got expert user lists from frequency of rating by item category.

\subsubsection{Experts from user like by item category}

This is an expert identification by using the preferences of the other users. The users who have more admiration from the other users will be represented as more professional skills. In this study, the preferences can be measured by using user rating from the other users. The user rating that will be taken into account will be only from target products and products from the same category of target products so that only the relevant products will be considered. The calculation can be shown as the following equation. 


$$
\text { AvgUserRatingCate } \text { A }_{A}=\frac{\sum_{i=1}^{N_{A} U R C_{A, i}}}{N_{A}}
$$

where AvgUserRatingCate ${ }_{A}$ is a mean user rating score of user $A$ in item category. $U R C_{A, i}$ is score that other users give to user $A$ from rating of target category and other products from the same item category, which $i \in\left\{1, \ldots, N_{A}\right\}$, and $N_{A}$ is frequency of user $A$ rating from the other users by item category. From this method, the researcher got expert user lists from user like by item category.

\subsection{Experts Neighbor Filtering Process}

In this process, there is a calculation of similarity between active users and expert users by using distanced based similarity method with data from User-item Matrix. Then, the expert neighbor will be ranked according to the evaluation in each type of expert identification; as follow, the experts from social network are ranked by Indegree. The experts from frequency of rating by item category are ranked by their frequency of product rating, and the experts from user like by item category are ranked by the average user rating score. Finally, TOP-N Method is used to filter expert neighbor users to be prepared for prediction process as shown in Fig. 3.

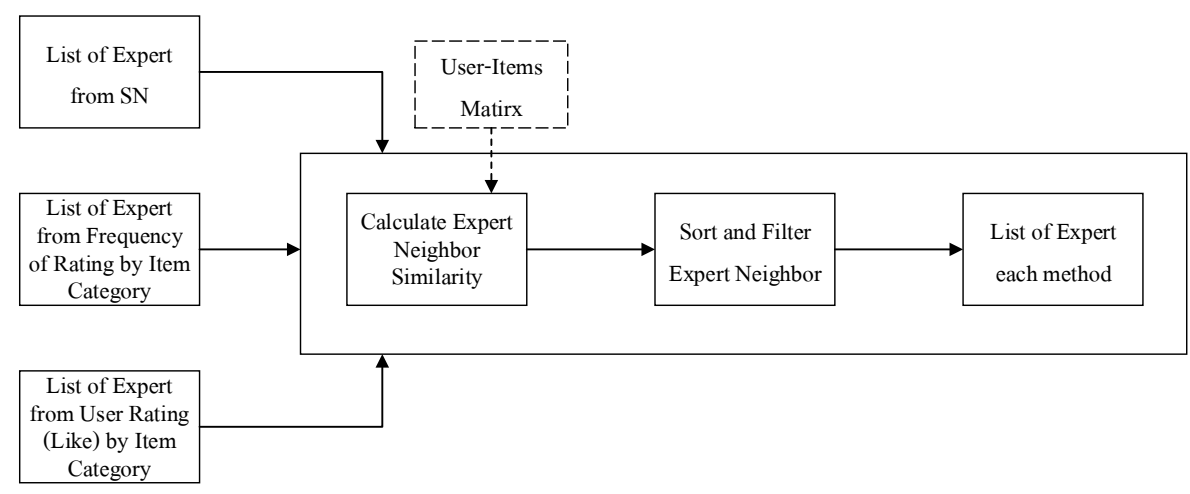

Fig. 3. Expert neighbor filtering process.

\subsection{Prediction Process}

This is the last process, and it is the prediction to give the points to target items for active users by using data from user-item matrix and the similarity points between users. The following equation was used for calculation $[4,22]$.

$$
P_{A x}=\overline{R_{A}}+\frac{\sum_{i=1}^{N}\left(\text { Similarity }_{A B, i} \times\left(R_{B x, i}-\overline{R_{B, i}}\right)\right)}{\sum_{i=1}^{N}\left(\text { Similarity }_{A B, i}\right)}
$$

where $A$ is an active user and $B$ is an expert user. $P_{A x}$ is score prediction result of $x$ target item from active user $A$. $R_{B x, i}$ is expert user $B$ score that expert user $B$ has for $x$ item. Similarity $y_{A B, i}$ is similarity points between active user $A$ and expert user $B, i \quad \overline{R_{A}}$ and $\overline{R_{B, l}}$ is mean score from item rating of active user $A$ and expert user $B, i$ respectively when $i \in\{1, \ldots, N\}$, and $N$ is the number of all users that rate score for $x$ target item.

After that, adjust prediction score in a defined range, and the result of this process indicates appropriability of target item for active users as shown in Fig. 4. 


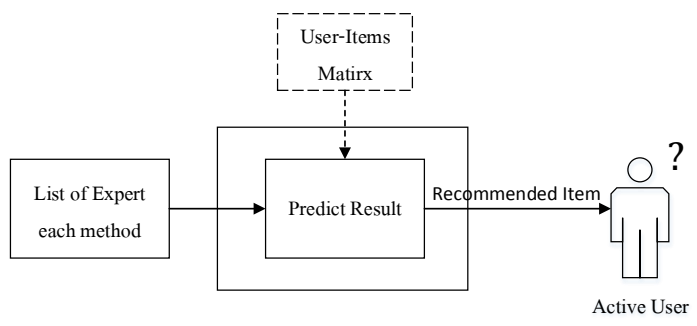

Fig. 4. Prediction process.

\section{Experiment}

In this part, the outcome of the experiment and comparison of recommender system performance are presented. It covers datasets, experiment setup, evaluation metrics, and evaluation results.

\subsection{Datasets}

There is a requirement to utilise data in this study; for example, rating item of users from the other user data, connection of users on social network data, and item category, so Epinion Datasets [25] is applied to this study. Epinion Datasets is derived from Epinions website where people can review and variously rate items in different categories: books, movies, music, etc. When the data is cleaned, there are 532,927 items rated from 20,355 users, and 30,738 items. The items are classified as 27 type, and one item can be classified in only one type. The rating scale is from $1-5$ level. Data density is at 0.085 . User network connecting is directed graph, and there is Helpfulness rating that is from $1-5$ level. To make sure that an experiment is correct, the researcher used K-Fold cross - validation, that were divided data into 5 folds, and 10 percentages blind data in each fold to test the prediction.

\subsection{Experiments Setup}

The expert neighbor filtering process is required to calculate the similarity between active users and expert users to be used for prediction calculate process; therefore, the popular distance-based similarity method [26] is applied, that are Manhattan Distance, Euclidean Distance, and Minkowski Distance as shown in following equation.

$$
\operatorname{Distance}(A, B)=\left(\sum_{i=1}^{N}\left|R_{A, i}-R_{B, i}\right|^{r}\right)^{1 / r}
$$

where $\operatorname{Distance}(A, B)$ is a distance between active user $A$ rating and expert user $B$ rating by various types of distance-based similarity method. $R_{A, i}$ and $R_{B, i}$ is $i$ item rating value of active user $A$ and expert user $B$ that $i \in\{1, \ldots, N\}$ while $N$ is the numbers of the same type item that user $A$ and user $B$ have rated, and $r$ is set as $1,2,3,4,5,10,50$ and 100 .

After that, the distance points of user rating are brought to be calculated into a similarity value by an ad hoc measurement of similarity, based on Euclidean Distance accordingly shown in the following equation.[27], [28].

$$
\operatorname{similarity}(A, B)=\frac{1}{1+\operatorname{Distance}(A, B)}
$$

where $\operatorname{similarity}(A, B)$ is similarity points between active user $A$ and expert user $B$ which are in $[0,1]$.

\subsection{Evaluation Metrics}

The evaluation of recommender system in this study is from popular methods that are error metrics and classification [29-31]. Error metrics, the researchers used two techniques that are Mean Absolute Error (MAR), and Root Mean Square Error (RMSE) as shown in the following equation. 


$$
\begin{aligned}
M A E & =\frac{1}{M} \sum_{j=1}^{M}\left|P_{\mathrm{U}, j}-R_{\mathrm{U}, j}\right| \\
R M S E & =\sqrt{\frac{1}{M} \sum_{j=1}^{M}\left(P_{\mathrm{U}, j}-R_{\mathrm{U}, j}\right)^{2}}
\end{aligned}
$$

where $P_{\mathrm{U}, \mathrm{j}}$ is a result of prediction rating value and $R_{\mathrm{U}, \mathrm{j}}$ is real rating value of user $\mathrm{U}$, that $j \in\{1, \ldots, M\}$ while $M$ is all items that are compared.

Classification metrics is information retrieval classification metrics used for measuring the correction of recommendation by using three methods; Accuracy, precision, and recall as shown in the following equation.

$$
\begin{gathered}
\text { Accuracy }=\frac{\text { True Positive }+ \text { True Negative }}{\text { True Positive }+ \text { False Positive }+ \text { True Negative }+ \text { False Negative }} \times 100 \\
\text { Precision }=\frac{\text { True Positive }}{\text { True Positive }+ \text { False Positive }} \\
\text { Recall }=\frac{\text { True Positive }}{\text { True Positive }+ \text { False Negative }}
\end{gathered}
$$

where True Positive is correct prediction that user is interested in item. False Positive is wrong prediction that user is interested in item. True Negative is correct prediction that user is not interested in item. And False Negative is wrong prediction that user is not interested in item.

\subsection{Evaluation Results}

From the experiment, 5 methods were compared to identify expert users that are 1) experts from network (ESN), 2) experts from frequency of rating by all items (EFA), 3) experts from frequency of rating by item category (EFC), 4) experts from user rating (like) by all items (ELA), and 5) expert from user rating (like) by item category (ELC) by using Epinion Dataset. The results are an average from 5 folds by using distance based similarity methods in different forms as shown in following tables.

Table 3. Mean value of MAEs of each expert identification by using distance based similarity methods.

\begin{tabular}{llllll}
\hline Measure & ESN & EFA & EFC & ELA & ELC \\
\hline Manhattan $r=1$ & 0.147 & 0.147 & 0.147 & $\mathbf{0 . 1 4 6}$ & 0.147 \\
Euclidean $\mathrm{r}=2$ & 0.147 & $\mathbf{0 . 1 4 6}$ & 0.147 & $\mathbf{0 . 1 4 6}$ & 0.147 \\
Minkowski $\mathrm{r}=3$ & 0.147 & $\mathbf{0 . 1 4 6}$ & 0.147 & $\mathbf{0 . 1 4 6}$ & 0.147 \\
Minkowski $\mathrm{r}=4$ & 0.147 & $\mathbf{0 . 1 4 6}$ & 0.147 & $\mathbf{0 . 1 4 6}$ & 0.147 \\
Minkowski $\mathrm{r}=5$ & 0.147 & $\mathbf{0 . 1 4 6}$ & 0.147 & $\mathbf{0 . 1 4 6}$ & 0.147 \\
Minkowski $\mathrm{r}=10$ & 0.147 & $\mathbf{0 . 1 4 6}$ & 0.147 & $\mathbf{0 . 1 4 6}$ & 0.147 \\
Minkowski $\mathrm{r}=50$ & 0.147 & $\mathbf{0 . 1 4 6}$ & 0.147 & $\mathbf{0 . 1 4 6}$ & 0.147 \\
Minkowski $\mathrm{r}=100$ & 0.147 & $\mathbf{0 . 1 4 6}$ & 0.147 & $\mathbf{0 . 1 4 6}$ & 0.147 \\
\hline
\end{tabular}

Table 4. Mean value of RMSEs of each expert identification by using distance based similarity methods.

\begin{tabular}{llllll}
\hline Measure & ESN & EFA & EFC & ELA & ELC \\
\hline Manhattan $r=1$ & 0.384 & 0.383 & 0.384 & 0.383 & 0.384 \\
Euclidean $\mathrm{r}=2$ & 0.383 & 0.383 & 0.383 & 0.383 & 0.384 \\
Minkowski $\mathrm{r}=3$ & 0.383 & 0.383 & 0.383 & $\mathbf{0 . 3 8 2}$ & 0.384 \\
Minkowski $\mathrm{r}=4$ & 0.383 & 0.383 & 0.383 & $\mathbf{0 . 3 8 2}$ & 0.384 \\
Minkowski $\mathrm{r}=5$ & 0.383 & 0.383 & 0.383 & $\mathbf{0 . 3 8 2}$ & 0.384 \\
Minkowski $\mathrm{r}=10$ & 0.383 & 0.383 & 0.383 & $\mathbf{0 . 3 8 2}$ & 0.384 \\
Minkowski $\mathrm{r}=50$ & 0.383 & 0.383 & 0.383 & $\mathbf{0 . 3 8 2}$ & 0.384 \\
Minkowski $\mathrm{r}=100$ & 0.383 & 0.383 & 0.383 & $\mathbf{0 . 3 8 2}$ & 0.384 \\
\hline
\end{tabular}


Table 5. Mean percentage of accuracy of each expert identification by using distance based similarity methods.

\begin{tabular}{lccccc}
\hline Measure & ESN & EFA & EFC & ELA & ELC \\
\hline Manhattan $r=1$ & 85.287 & 85.334 & 85.286 & $\mathbf{8 5 . 3 5 7}$ & 85.261 \\
Euclidean $\mathrm{r}=2$ & 85.295 & 85.354 & 85.298 & $\mathbf{8 5 . 3 6 4}$ & 85.281 \\
Minkowski $\mathrm{r}=3$ & 85.297 & $\mathbf{8 5 . 3 6 1}$ & $\mathbf{8 5 . 2 9 8}$ & $\mathbf{8 5 . 3 6 8}$ & $\mathbf{8 5 . 2 8 2}$ \\
Minkowski $\mathrm{r}=4$ & 85.298 & 85.359 & 85.295 & $\mathbf{8 5 . 3 6 7}$ & 85.280 \\
Minkowski $\mathrm{r}=5$ & 85.296 & 85.359 & 85.294 & $\mathbf{8 5 . 3 6 8}$ & 85.281 \\
Minkowski $\mathrm{r}=10$ & 85.297 & 85.358 & 85.293 & $\mathbf{8 5 . 3 6 8}$ & 85.280 \\
Minkowski $\mathrm{r}=50$ & 85.294 & 85.358 & 85.292 & $\mathbf{8 5 . 3 6 7}$ & 85.278 \\
Minkowski $\mathrm{r}=100$ & 85.294 & 85.358 & 85.293 & $\mathbf{8 5 . 3 6 8}$ & 85.277 \\
\hline
\end{tabular}

Table 6. Mean precision score of each expert identification by using distance based similarity methods.

\begin{tabular}{llllll}
\hline Measure & ESN & EFA & EFC & ELA & ELC \\
\hline Manhattan $\mathrm{r}=1$ & 0.979 & 0.980 & 0.980 & $\mathbf{0 . 9 8 1}$ & 0.975 \\
Euclidean $\mathrm{r}=2$ & 0.979 & 0.981 & 0.980 & $\mathbf{0 . 9 8 2}$ & 0.976 \\
Minkowski $\mathrm{r}=3$ & 0.979 & 0.981 & 0.980 & $\mathbf{0 . 9 8 2}$ & 0.976 \\
Minkowski $\mathrm{r}=4$ & 0.979 & 0.981 & 0.980 & $\mathbf{0 . 9 8 2}$ & 0.976 \\
Minkowski $\mathrm{r}=5$ & 0.979 & 0.981 & 0.980 & $\mathbf{0 . 9 8 2}$ & 0.976 \\
Minkowski $\mathrm{r}=10$ & 0.979 & 0.981 & 0.980 & $\mathbf{0 . 9 8 2}$ & 0.976 \\
Minkowski $\mathrm{r}=50$ & 0.979 & 0.981 & 0.980 & $\mathbf{0 . 9 8 2}$ & 0.976 \\
Minkowski $\mathrm{r}=100$ & 0.979 & 0.981 & 0.980 & $\mathbf{0 . 9 8 2}$ & 0.976 \\
\hline
\end{tabular}

Table 7. Mean recall score of each expert identification by using distance based similarity methods.

\begin{tabular}{llllll}
\hline Measure & ESN & EFA & EFC & ELA & ELC \\
\hline Manhattan $r=1$ & 0.866 & 0.866 & 0.866 & 0.865 & $\mathbf{0 . 8 6 8}$ \\
Euclidean $r=2$ & 0.866 & 0.866 & 0.866 & 0.865 & $\mathbf{0 . 8 6 8}$ \\
Minkowski $r=3$ & 0.866 & 0.866 & 0.866 & 0.865 & $\mathbf{0 . 8 6 8}$ \\
Minkowski $\mathrm{r}=4$ & 0.866 & 0.866 & 0.866 & 0.865 & $\mathbf{0 . 8 6 8}$ \\
Minkowski $\mathrm{r}=5$ & 0.866 & 0.866 & 0.866 & 0.865 & $\mathbf{0 . 8 6 8}$ \\
Minkowski $\mathrm{r}=10$ & 0.866 & 0.866 & 0.865 & 0.865 & $\mathbf{0 . 8 6 8}$ \\
Minkowski $\mathrm{r}=50$ & 0.866 & 0.866 & 0.865 & 0.865 & $\mathbf{0 . 8 6 8}$ \\
Minkowski $\mathrm{r}=100$ & 0.866 & 0.866 & 0.865 & 0.865 & $\mathbf{0 . 8 6 8}$ \\
\hline
\end{tabular}

Considering error metrics from Table 3 and Table 4, obviously MAE mean is about 0.15, and RMSE mean is about 0.38 in all methods compared; however, when looking carefully, EFA and ELA have the lowest error scores in all methods compared. As shown from Table 5 to Table 7, the classification metrics result showed that mean percentage of accuracy is approximately $85 \%$; mean precision score is about 0.98 ; and mean recall score is about 0.87 . In particular, the mean percentage of accuracy and mean precision score of ELA are higher than any others. The highest mean recall score is with ELC. When comparing results of different distance based similarity methods from each expert identification method, the results are not different.

An overview of the experiment suggest that ELA with no using item category is more efficient; however, there is small different when it is compared to the other methods.

Consequently, the researcher compared time used for recommendation creating process between process with item category and process with no item category. There are two features to compare; 1) average time for processing when data size is changing and 2) average time for processing when it compares with percentage of accuracy as shown in Fig. 5 and Fig. 6. As shown in pictures, process with item category can be reduced 60 percentages of processing time for recommendation. 


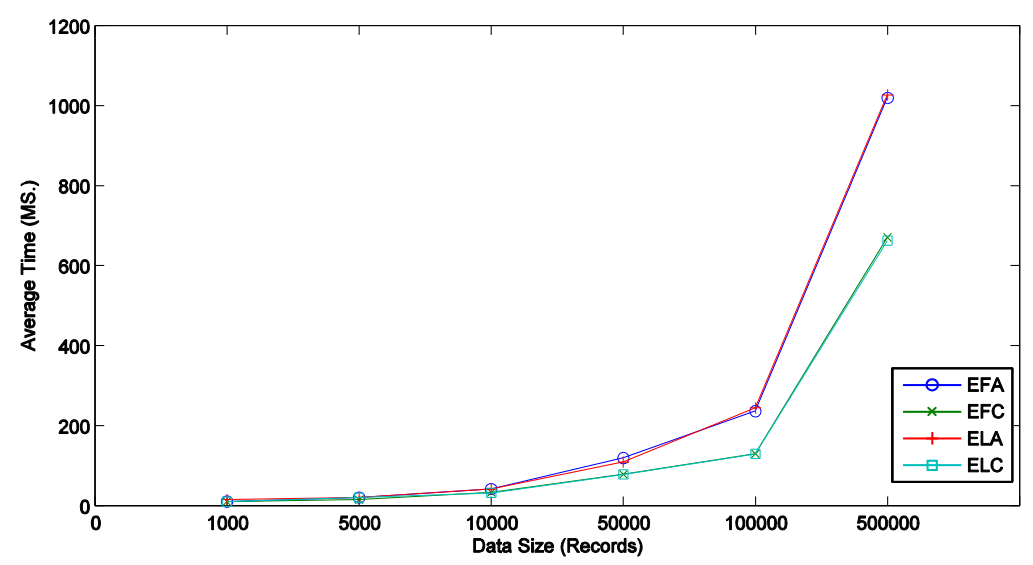

Fig. 5. The average processing time with changing data size.

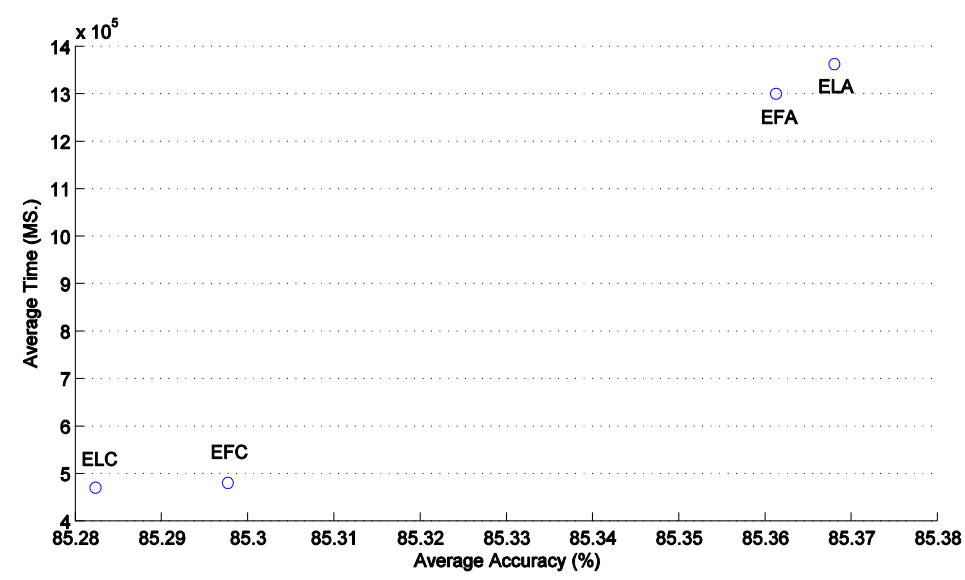

Fig. 6. The average processing time compare with average percentage of accuracy.

To conclude an overview of this study, the researcher found out that there is about 85 percentage of accuracy for all expert identification method. When comparing each expert identification technique, the researcher found out that an expert from user rating (like) by all items is the best efficient for recommendation prediction because the database is more complied with this technique. However, there is not much different in all expert identification methods and all distance based similarity methods, yet considering about the processing time of creating recommendation, the expert identification process with item category can help reduce processing time because it is the data filter before recommendation creating.

\section{Conclusion and Discussion}

This study presented the recommender system based on expert and item category by 3 types of expert identification techniques that are firstly, the expert from social network technique, expert from frequency of user rating technique, and lastly, the expert from other user's preference technique by using item category to identify experts from frequency of user rating and other user's preference. The advantages of the proposed research demonstrate the application of expert concepts, together with item category for recommended items. Although the results is not the highest accuracy, but it can greatly reduce the processing time. Also, the research has limitations among the experts from social network method which does not support Sybil Attack problem that may effect on the correctness of the degree calculation of neighbor user in social network. In the future, suggestively, trustworthy might be applied with experts to improve recommendation performance. 


\section{References}

[1] A. Albadvi and M. Shahbazi, "A hybrid recommendation technique based on product category attributes," Expert Syst. Appl., vol. 36, no. 9, pp. 11480-11488, Nov. 2009.

[2] G. Guo, J. Zhang, and D. Thalmann, "Merging trust in collaborative filtering to alleviate data sparsity and cold start," Knowl.-Based Syst., vol. 57, pp. 57-68, Feb. 2014.

[3] E. Q. da Silva, C. G. Camilo-Junior, L. M. L. Pascoal, and T. C. Rosa, "An evolutionary approach for combining results of recommender systems techniques based on collaborative filtering," Expert Syst. Appl., vol. 53, pp. 204-218, Jul. 2016.

[4] Y.-M. Li, C.-T. Wu, and C.-Y. Lai, "A social recommender mechanism for e-commerce: Combining similarity, trust, and relationship," Decis. Support Syst., vol. 55, no. 3, pp. 740-752, Jun. 2013.

[5] J. Bobadilla, F. Ortega, A. Hernando, and A. Gutiérrez, "Recommender systems survey," Knowl.-Based Syst., vol. 46, pp. 109-132, Jul. 2013.

[6] Z. Sun, L. Han, W. Huang, X. Wang, X. Zeng, M. Wang, and H. Yan, "Recommender systems based on social networks," J. Syst. Softw., vol. 99, pp. 109-119, Jan. 2015.

[7] L. Zhang, J. Xu, and C. Li, "A random-walk based recommendation algorithm considering item categories," Image Feature Detect. Descr., vol. 120, pp. 391-396, Nov. 2013.

[8] J. Lu, D. Wu, M. Mao, W. Wang, and G. Zhang, "Recommender system application developments: A survey," Decis. Support Syst., vol. 74, pp. 12-32, Jun. 2015.

[9] G. Adomavicius and A. Tuzhilin, "Toward the next generation of recommender systems: A survey of the state-of-the-art and possible extensions," IEEE Trans. Knowl. Data Eng., vol. 17, no. 6, pp. 734 749, 2005.

[10] Q. Shambour and J. Lu, "A trust-semantic fusion-based recommendation approach for e-business applications,” Decis. Support Syst., vol. 54, no. 1, pp. 768-780, Dec. 2012.

[11] A. Jøsang, R. Ismail, and C. Boyd, "A survey of trust and reputation systems for online service provision,” Emerg. Issues Collab. Commer., vol. 43, no. 2, pp. 618-644, Mar. 2007.

[12] A. Asawachatroj and D. Banjerdpongchai, "Analysis of advanced process control technology and economic assessment improvement," Engineering Journal (Eng. J.), vol. 16, no. 4, pp. 1-4, Jun. 2012.

[13] M. I. Martin-Vicente, A. Gil-Solla, M. Ramos-Cabrer, Y. Blanco-Fern'ndez, and M. Lopez-Nores, "Improving e-commerce collaborative recommendations by semantic inference of neighbors' practical expertise," in 2011 Sixth International Workshop on Semantic Media Adaptation and Personalization (SMAP), 2011, pp. 9-14.

[14] M. Li, L. Liu, and C.-B. Li, "An approach to expert recommendation based on fuzzy linguistic method and fuzzy text classification in knowledge management systems," Expert Syst. Appl., vol. 38, no. 7, pp. 8586-8596, Jul. 2011.

[15] M. T. Afzal, and H. A. Maurer, "Expertise Recommender System for Scientific Community," J UCS, vol. 17, no. 11, pp. 1529-1549, 2011.

[16] Q. V. Liao, C. Wagner, P. Pirolli, and W.-T. Fu, “Understanding experts' and novices' expertise judgment of twitter users," in Proceedings of the SIGCHI Conference on Human Factors in Computing Systems, 2012, pp. 2461-2464.

[17] S. Song, S. Lee, S. Park, and S. Lee, "Determining user expertise for improving recommendation performance," in Proceedings of the 6th International Conference on Ubiquitous Information Management and Communication, 2012, p. 67.

[18] Y.-M. Li, T.-F. Liao, and C.-Y. Lai, “A social recommender mechanism for improving knowledge sharing in online forums," Large-Scale Distrib. Syst. Inf. Retr., vol. 48, no. 5, pp. 978-994, Sep. 2012.

[19] E. Davoodi, K. Kianmehr, and M. Afsharchi, "A semantic social network-based expert recommender system," Appl. Intell., vol. 39, no. 1, pp. 1-13, 2013.

[20] S. M. Choi and Y. S. Han, "A content recommendation system based on category correlations," in 2010 Fifth International Multi-Conference on Computing in the Global Information Technology (ICCGI), 2010, pp. $66-70$.

[21] S. Wei, N. Ye, S. Zhang, X. Huang, and J. Zhu, "Item-based collaborative filtering recommendation algorithm combining item category with interestingness measure," in 2012 International Conference on Computer Science \& Service System (CSSS), 2012, pp. 2038-2041.

[22] T. Phukseng, N. Wisitpongphan, and S. Sodsee, "Applying item category rating in recommendation systems," in The 2nd Management Innovation Technology International Conference, Thailand, 2015, pp. 155158. 
[23] D. Wu, L. Bao, A. C. Regan, and C. L. Talcott, "Large-scale access scheduling in wireless mesh networks using social centrality," J. Parallel Distrib. Comput., vol. 73, no. 8, pp. 1049-1065, 2013.

[24] X. Molinero, F. Riquelme and M. Serna, "Power indices of influence games and new centrality measures for social networks," ArXiv Prepr. ArXiv13066929, 2013.

[25] Librec. (2015). Product Review Datasets: Epinions and Ciao [Online]. Available: http://www.librec.net/datasets.html [Accessed: 12 Nov. 2015]

[26] J. F. D'Souza, C. K. Adams, and A. Reed, "Validation of region-based crossover for clustering problems," Int. J. Imaging Robot., vol. 15, no. 2, pp. 53-66, 2015.

[27] E. Winarko, S. Hartati, and R. Wardoyo, "Improving the prediction accuracy of multicriteria collaborative filtering by combination algorithms," Int. J. Adv. Comput. Sci. App, vol. 52, no. 4, pp.52$58,2014$.

[28] H. Shimodaira, "Similarity and recommender systems," Sch. Inform. Univ. Eidenburgh, 2014.

[29] F. Xie, Z. Chen, J. Shang, and G. C. Fox, "Grey forecast model for accurate recommendation in presence of data sparsity and correlation," Knowl.-Based Syst., vol. 69, pp. 179-190, Oct. 2014.

[30] J. Areeyapinan, P. Kanongchaiyos, and A. Kawewong, "Using multi-descriptors for real time cosmetic image retrieval," Engineering Journal (Eng. J.), vol. 18, no. 4, pp. 97-111, Oct. 2014.

[31] T. Chuosavasdi, B. Stitmannaithum, T. Sumranwanich, W. Saengsoy, and S. Tangtermsirikul, "Degree of hydration and mass balance equations for determination of mix proportion of hardened OPC concrete," Engineering Journal (Eng. J.), vol. 20, no. 2, pp. 211-219, May 2016. 